\title{
台金の温度分布を利用した丸鋸の腰入れ*
}

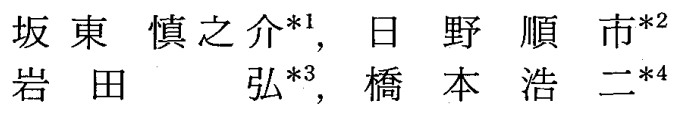

\section{The Tensioning for a Tipped Saw Using the Temperature Distribution on Its Base Metal}

\author{
Shinnosuke BANDO*5, Junichi HINO, \\ Hiromu IWATA and Koji HASHIMOTO \\ *5 Kagawa Pref. Industrial Technology Center, \\ 587-1 Goto-cho, Takamatsu-shi, Kagawa, 761-8031 Japan
}

\begin{abstract}
In this paper, we considered a new tensioning method by the temperature distribution on the base metal of tipped saw. First, the relationship of the temperature distribution on the base metal and the tensioning effect (i. e. transitions of natural frequency) was examined by calculation using a disk model. As the results, when the temperature $\Theta_{c}$ at inner circumference of the disk was higher than the temperature $\Theta_{a}$ at outer circumference, the natural frequency of the two or higher nodal diameters mode increased. And the increments of the natural frequencies were proportional to the temperature deference $\Theta_{c}-\Theta_{a}$. Furthermore, the tangential residual stress $\sigma_{\theta}$ at outer of disk had positive value denoted as tensile stress. These results coincided with the effects of the traditional tensioning method so called 'Roll Tensioning'. Then, the validity of the calculation results by experiment using disk was verified. The transition of the natural frequency by the experiments indicated similar tendency to the calculation results.
\end{abstract}

Key Words : Vibration of Continuous System, Modal Analysis, Natural Frequency, Tipped Saw, Tensioning Effect, Temperature Distribution, Thermal Stress, Disk

\section{1. 緒言}

丸鋸(図 $\left.1^{(1)}\right)$ は，非鉄金属，木材，鉄鋼材料など，各 種素形材の切断に幅広く用いられる工具である。丸鋸 は，薄板回転円板であることから，空転時及び切断作 業中に, 面外方向への振動が生じやすい構造となって いる. 特に, 台金の固有振動数と主軸回転数が共振を 生じる危険回転数においては, 大振幅の振動が生じる ため，その対策が必須となっている。

丸鋸の面外振動や危険回転数への対策のうち，代表 的な方法にローラ腰入れ(2) がある(図2)。この方法 は，低速で回転する丸鋸の台金に対し，その表裏両面 からローラを押し付け, かつローラを台金の半径方向 に移動させることにより，台金に広く残留応力を付与 する塑性加工である。この処理により, 台金の㓘性を 変化させ, 実用回転数領域で問題となりやすい $(0, n)$

* 原稿受付 2010 年 7 月 26 日.

*1 正員，香川県産業技術センター(画761-8031 高松市郷東町 $587-1)$.

*2 正員, 徳島大学大学院ソシオテクノサイエンス研究部 (昰770-8506 徳島市南常三島町 2-1)

*3 正員, 香川高等専門学校機械工学科(画 761-8058 高松市栜 使町 355).

*4 橋本特殊工業 (株) (画760-0064 高松市朝日新町 30-8).

E-mail : bando@itc.pref.kagawa.jp
次モード (節円数 0 , 節直径数 $n, n \geqq 2)$ の固有振動数 を増大させることができる。

一般に, 腰入れに扔けるローラ圧力の調整は，手作

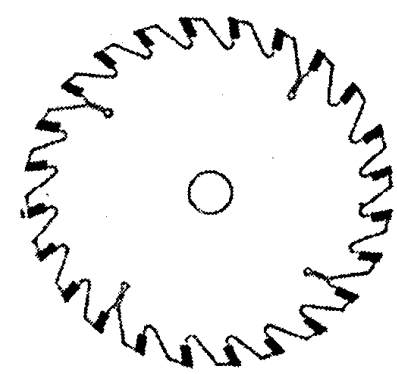

Fig. 1 Tipped saw ${ }^{(1)}$

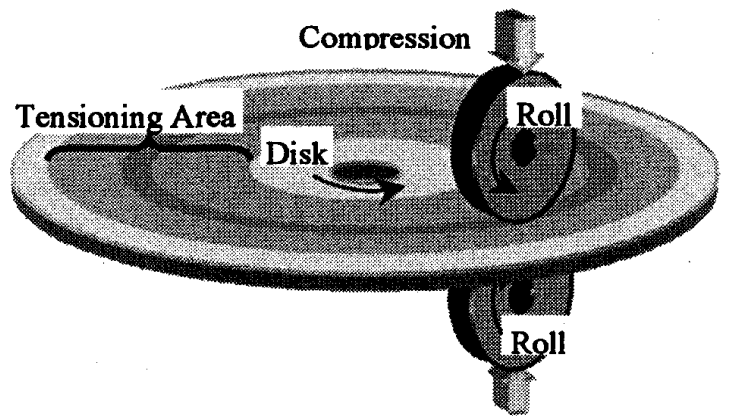

Fig. 2 Roll tensioning 
業によって行われる。このため, ローラ腰入れの結果 は，作業者の熟練度合いに依存する．ローラ圧力が大 きすぎる場合には，台金が血型 $[(0,0)$ 次モード形状 $]$ に座屈するといった欠点もある(2).

ところで, 近年, 切屑排出量の低隇を目的として, 丸鋸の薄型化への要望が高くなうている，しかし，薄 型化した台金にローラ腰入れを行う場合，ローラ圧力 の調整は更に困難となる。

このことに対し，これまでにも，塑性加工を伴わな い腰入れとして, $\mathrm{CO}_{2}$ レーザによる残留応力付与(3), 熱処理過程で残留応力を付与する方法(4) などが提案 されている，ただし，いずれも台金金属の局所的な金 属組織の変質を伴う方法であり, 熱影響部を起点とす る割れの発生が懸念されるなど, 課題が残されてい る.

そこで本研究では，丸鋸の台金に，温度分布に伴う 熱応力を生じさせることによって, 腰入れ効果を付与 する方法について検討した，具体的には，円板モデル を用いて, 内外周温度差に起因する熱応力と丸鋸の固 有振動数の関係について, 解析的に求めた. また解析 方法の妥当性については，実験に基づき評価した。

\section{2. 解 析}

2・1 円板の固有振動数 ${ }^{(2)(5)}$ 本研究においては, 丸鋸を円板モデルに置き換えて解析を行い，固有振動 数の推移を検討する. 円板の諸元をに表 1 に示す.

半径 $r$, 円周角 $\theta$ とする円柱座標系において, 円板 の自由振動を表す運動方程式は，次式のように表すこ とができる。

$$
D D^{4} w+\rho h \frac{\partial^{2} w}{\partial t^{2}}=0
$$

ここで, $D$ は円板の曲げ剛性, $\nabla$ は円柱座標系でのラ プラシアン演算子であり，以下のように表される。

$$
\begin{aligned}
D & =\frac{E h^{3}}{12\left(1-\nu^{2}\right)} \\
\nabla^{2} & =\frac{\partial^{2}}{\partial r^{2}}+\frac{1}{r} \frac{\partial}{\partial r}+\frac{1}{r^{2}} \frac{\partial^{2}}{\partial^{2} \theta}
\end{aligned}
$$

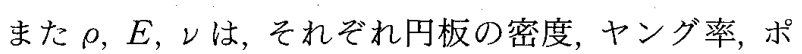

Table 1 Specifications of the disk for experiment

\begin{tabular}{l|c}
\hline Material & SKS5 \\
(Young modulus $E[\mathrm{~Pa}]$ ) & $\left(2.1 \times 10^{11}\right.$ ) \\
(Density $\quad \rho\left[\mathrm{kg} / \mathrm{m}^{3}\right]$ ) & $(7850)$ \\
(Poisson ratio $v$ ) & $(0.3)$ \\
\hline Outer diameter $2 a[\mathrm{~mm}]$ & 305 \\
\hline Inner diameter $2 b[\mathrm{~mm}]$ & 32 \\
\hline Flange's diameter $2 c[\mathrm{~mm}]$ & 78 \\
\hline Thickness $\quad h[\mathrm{~mm}]$ & 1.1 \\
\hline
\end{tabular}

アソン比である.

式 (1)において, $(m, n)$ 次モードの円板のたわみ 曲線 $w_{m n}$ を, 半径 $r$, 円周角 $\theta$, 時間 $t$ の関数として, 以下のように仮定する。

$$
w_{m n}(r, \theta, t)=R_{m n}(r) \cdot \sin (n \theta) \cdot \sin \left(\omega_{m n} t\right)
$$

ここで, $\omega_{m n}$ は, $(m, n)$ 次モードの固有角振動数であ る. 式 (1),（2）を用い, 半径 $r$ にいて整理すると, ベッセル型の微分方程式となり， $R_{m n}(r)$ の一般解が 得られる。

$$
\begin{aligned}
& R_{m n}(r)=\alpha_{m n} J_{n}\left(\kappa_{m n} r\right)+\beta_{m n} Y_{n}\left(\kappa_{m n} r\right) \\
& \quad+\gamma_{m n} I_{n}\left(\kappa_{m n} r\right)+\delta_{m n} K_{n}\left(\kappa_{m n} r\right) \cdots \cdots . .
\end{aligned}
$$

$J_{n}\left(\kappa_{m n} r\right), Y_{n}\left(\kappa_{m n} r\right)$ は $n$ 次ベッセル関数, $I_{n}\left(\kappa_{m n} r\right)$, $K_{n}\left(\kappa_{m n} \gamma\right)$ は $n$ 次変形べッセル関数であり, $\alpha_{m n}, \beta_{m n}$, $\gamma_{m n}, \delta_{m n}$ は $(m, n)$ 次の振動モード固有の係数, $\kappa_{m n}{ }^{4}=$ $\rho h \omega_{m n}^{2} / D$ である。

境界条件は, フランジ部 $(r=c)$ に打いて完全固定

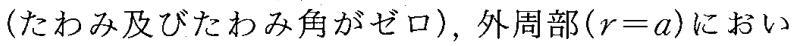
て自由端(曲げモーメント及びせん断力がゼロ)の条件 とした．これらの境界条件に対し，式(2)，（3)で表 される一般解を代入, 整理することによって得られる 行列式から, 円板の固有振動数を求めることができ る.

一方，円板に面内応力が生じる場合には，解析にお いても，その影響を考慮する必要がある，そこで，面 内応力がある場合の雪みエネルギーの変化量を求め る. 面外方向へ $(m, n)$ 次モードで振動している円板 の運動エネルギー $T_{m n}$ は,

$$
T_{m n}=\frac{\rho h}{2} \int_{c}^{a} \int_{-\pi}^{\pi}\left(\frac{\partial w_{m n}}{\partial t}\right)^{2} r \mathrm{~d} r \mathrm{~d} \theta
$$

と表せる.また面外振動に起因する歪エネルギー Unn は,

$$
\begin{aligned}
& U_{m n}=\int_{c}^{a} \int_{-\pi}^{\pi} \frac{1}{2} D\left\{\left(\nabla^{2} w_{m n}\right)^{2}\right. \\
& -2(1-\nu) \frac{\partial^{2} w_{m n}}{\partial r^{2}}\left(\frac{1}{r} \frac{\partial w_{m n}}{\partial r}+\frac{1}{r^{2}} \frac{\partial^{2} w_{m n}}{\partial \theta^{2}}\right) \\
& \left.+2(1-\nu)\left[\frac{\partial}{\partial r}\left(\frac{1}{r} \frac{\partial w_{m n}}{\partial \theta}\right)\right]\right\} r \mathrm{~d} r \mathrm{~d} \theta \cdots \cdots
\end{aligned}
$$

で表される．更に，円板面内に応力が分布している場 合, 面外振動変位が生じる際の歪エネルギーには，次 式で示すようなエネルギー変化が生じる。

$$
\begin{gathered}
\Delta U_{m n}=\frac{h}{2} \int_{c}^{a} \int_{-\pi}^{\pi}\left\{\sigma_{r}\left(\frac{\partial w_{m n}}{\partial r}\right)^{2}\right. \\
\left.+\sigma_{\theta}\left[\frac{1}{r}\left(\frac{\partial w_{m n}}{\partial \theta}\right)\right]^{2}\right\} r \mathrm{~d} r \mathrm{~d} \theta .
\end{gathered}
$$

ここで, $\sigma_{r}$ は半径方向応力, $\sigma_{\theta}$ は接線方向応力であ る.式(4)〜（6）によって得られた各エネルギーの間 には，エネルギー保存則に基づき， 
$\left.T_{m n}\right|_{\max }=\left.\left(U_{m n}+\Delta U_{m n}\right)\right|_{\max }$

が成立する。

式 (6)より, 面内応力 $\sigma_{r}, \sigma_{\theta}$ の符号及びその分布に よって, $\Delta U_{m n}$ の符号も変化することが分かる. 式 （7）と併せて考えると, $\Delta U_{m n}$ が正の值を示すモード においては, 固有振動数が増大し, 負の值を示すモー ドにおいては，固有振動数が減少することが分かる。 これらのことを利用して，円板に面内応力が生じてい る場合の固有振動数を求めることができる.

$2 \cdot 2$ 熱応力の定義 円板の半径方向に温度分布 が生じた場合の面内熱応力が, 固有振動数に及ぼす影 響について検討した。，具体的には，半径方向の温度分 布を, 次式のと扔り, 定常熱伝導状態と仮定した。こ こでは, 問題の簡単化のため, 円板表面から外部空気 への熱伝達は省略して取り扱うこととした。

$$
\begin{aligned}
& \frac{\Theta_{c}-\Theta(r)}{\Theta_{c}-\Theta_{a}}=\frac{\ln (r / c)}{\ln (a / c)} \\
& \rightarrow \Theta(r)=\frac{\Theta_{c} \ln (a / r)+\Theta_{a} \ln (r / c)}{\ln (c / a)}
\end{aligned}
$$

ここで, $\Theta(r)$ は円板における半径方向温度分布, $\Theta_{c}$ は内周(フランジ部, $r=c$ )における温度, $\Theta_{a}$ は外 周 $(r=a)$ における温度を表している. 熱応力は, 初 期温度 $\Theta_{0}$ に対する温度変化量に基づき発生する.こ こでは, 温度変化量の半径方向への分布を $\Delta \Theta(r)$ と し，また式 $(8)$ を変形して，次式のように定義する。

$$
\begin{aligned}
& \Delta \Theta(r)=\Theta(r)-\Theta_{0} \\
& \quad=\frac{\Theta_{c} \ln (a / r)+\Theta_{a} \ln (r / c)}{\ln (c / a)}-\Theta_{0}
\end{aligned}
$$

最終的に，式(9)を以下の式に代入するごとにより， 熱応力を求めることができる.

$$
\begin{aligned}
\sigma_{r} & =-\frac{\alpha E}{r^{2}} \int_{c}^{a} \Delta \Theta(r) \cdot r \cdot \mathrm{d} r \\
& +\frac{E}{1-\nu^{2}}\left[C_{1}(1+\nu)-C_{2}(1-\nu) \frac{1}{r^{2}}\right] \quad \ldots \\
\sigma_{\theta} & =\frac{\alpha E}{r^{2}} \int_{-\pi}^{\pi} \Delta \Theta(r) \cdot r \cdot \mathrm{d} r-\alpha \cdot E \cdot \Delta \Theta(r) \\
& +\frac{E}{1-\nu^{2}}\left[C_{1}(1+\nu)+C_{2}(1-\nu) \frac{1}{r^{2}}\right] \ldots
\end{aligned}
$$

ただし， $C_{1} ， C_{2}$ はそれぞれ，

$$
C_{\mathrm{l}}=-\frac{\alpha\left(1-\nu^{2}\right) \int_{c}^{a} \Delta \Theta(r) \cdot r \cdot \mathrm{d} r}{(1+\nu) a^{2}+(1-\nu) c^{2}}, \quad C_{2}=-c^{2} \cdot C_{1}
$$

であり, $\alpha$ は線膨張係数である.

以上より, 式 $(9) \sim(11)$ を用いて熱応力を求めた後, 式 (4)〜（7）を解くことによって, 熱応力が生じる円 板の固有振動数を求めた.

$2 \cdot 3$ 熱応力の腰入れ効果(解析結果) 前節まで に示した解析を実施することにより, 円板の固有振動 数の変化を求めた. 解析に扔いては, 初期温度 $\Theta_{0}=$ $25^{\circ} \mathrm{C}$ (室温)，また円板外周温度 $\Theta_{a}=28^{\circ} \mathrm{C}$ (一定)に設 定した.フランジ部に相当する内周側温度 $\Theta_{c}$ を変化 させることにより, 内外周温度差を与えた，固有振動 数の推移を求めた結果を図 3 に示す。ここでは, 内周 側温度と外周側温度の差を横軸にとっており， $\Theta_{c}$ $-\Theta_{a}>0$ の範囲は内周側が高温, $\Theta_{c}-\Theta_{a}<0$ の範囲は 外周側が高温となる状態にそれぞれ対応している.

図 3 から， $\Theta_{c}-\Theta_{a}>0$ の範囲では，内外周温度差が 大きくなるにつれて, $(0,0)$ 次, $(0,1)$ 次モードの固有 振動数が下がり, 逆に $(0,2)$ 次以上の高次モードの固 有振動数が高くなる傾向が得られた.この傾向は, 口 ーラ腰入れにおける付加応力の増大に対する固有振動 数変化の関係 ${ }^{(2)}$ と同じ結果である.

一方, $\Theta_{c}-\Theta_{a}<0$ の範囲では, 内外周温度差が大き くなるにつれて, $(0,0)$ 次, $(0,1)$ 次の固有振動数が高 くなり, $(0,2)$ 次以上の高次モードの固有振動数が下 がることが確認できた，木材の切断においては，被削 材による鋸身 (台金)の挟み込みによって, 刃先近傍の 温度が上昇しやすく，熱座屈を生じやすいことが知ら れている(7). $\Theta_{c}-\Theta_{a}<0$ の範囲における $(0,2)$ 次以上 の高次モードの固有振動数低下は, 切断中の熱座屈に 対応すると考えられる。

以上の解析結果から, 台金に対して $\Theta_{c}-\Theta_{a}>0$ の 条件を満たす温度分布を与えることにより，ローラ腰 入れと同様の効果が得られるものと考えられる。

次に, 面内熱応力の例として, 内周側温度 $\Theta_{c}=$ $48^{\circ} \mathrm{C}$, 外周側温度 $\Theta_{a}=28^{\circ} \mathrm{C}$, 初期温度 $\Theta_{0}=25^{\circ} \mathrm{C}$ に お ける半径方向の面内応力分布を図 4 に，またこのとき の半径方向温度分布 $\Theta(r)$ を図 5 に示す。図 4 より, 面内熱応力のうち, 接線方向応力 $\sigma_{\theta}$ が, 外周 (刃先) 近 傍において引張の值を示すことがわかった，図示して いないが, $\Theta_{c}-\Theta_{a}>0$ の条件を満たす温度分布を与え た場合, 全ての条件において, 外周近傍の $\sigma_{\theta}$ が引張の 值を示した。

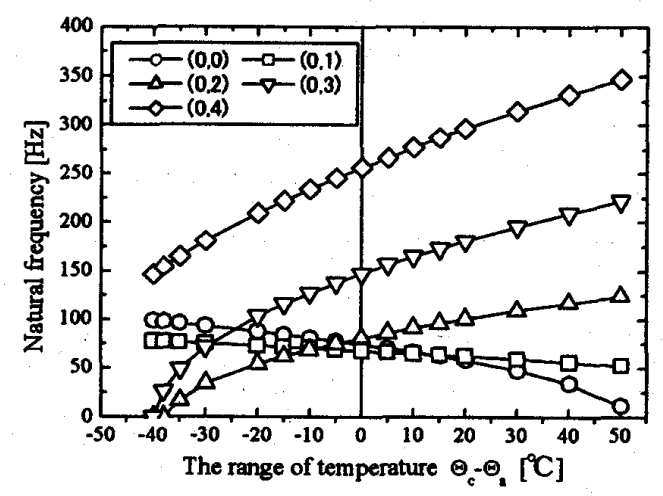

Fig. 3 Transition of natural frequency of disk 


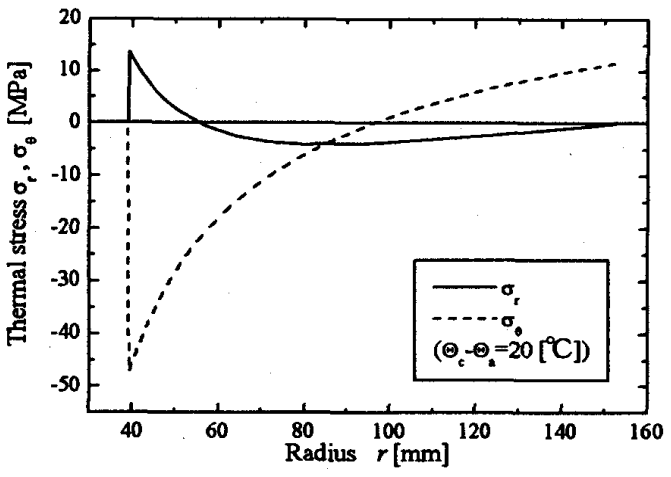

Fig. 4 Thermal stress on disk

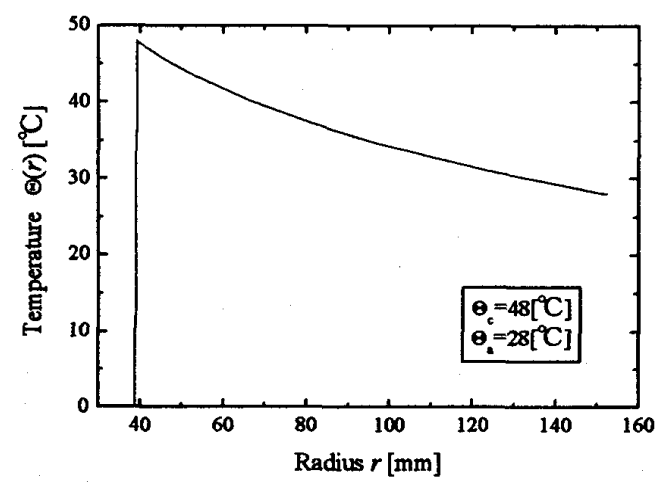

Fig. 5 Temperature distribution on disk

ローラ腰入れに扔いては，接線方向面内応力が，外 周近傍において引張となる特徵がある. 実際の切断作 業時には，刃先に対して圧縮の切断抵抗が作用するが， 接線方向の引張応力が残留するというローラ腰入れの 特徵により，座屈が生じにくくなる利点がある。本研 究のように, $\Theta_{c}-\Theta_{a}>0$ となる温度分布を与えること で, 面内応力分布の観点からも，ローラ腰入れと同等 の効果が得られることが確認できた。

\section{3. 実験}

$3 \cdot 1$ 実験装置及び実験方法 前章までの解析結 果の妥当性を検証するため, 円板モデルによる実験を 行った，実験装置の模式図を図 6 に示す，実験におい ても，表 1 に示した円板を用いた。また，実際の切断 機において，丸鋸の内周側を加熱することができる方 法として，モータ回転軸の発熱を利用することとし た。まず円板をモータ主軸に取り付け，回転数を $1500,3000,5000 \mathrm{rpm}$ に設定し，最長 120 分間空転 させた。この方法により加熱された円板の温度分布の 推移を計測し, 定常状態に達するまでの時間を確認し た.円板の温度分布測定においては，赤外線熱画像計 測装置(ニコン, LAIRD 3)を用いた。

また, 円板上の温度分布が定常状態に達した後, 腰

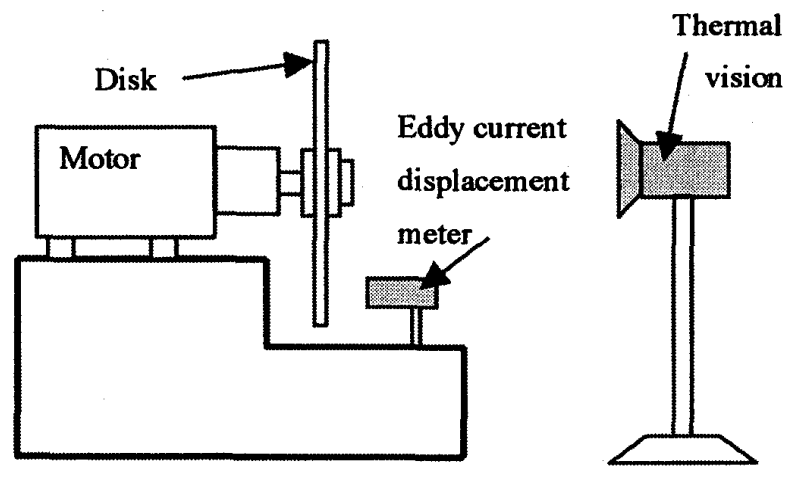

Fig. 6 Schematic diagram of experiment

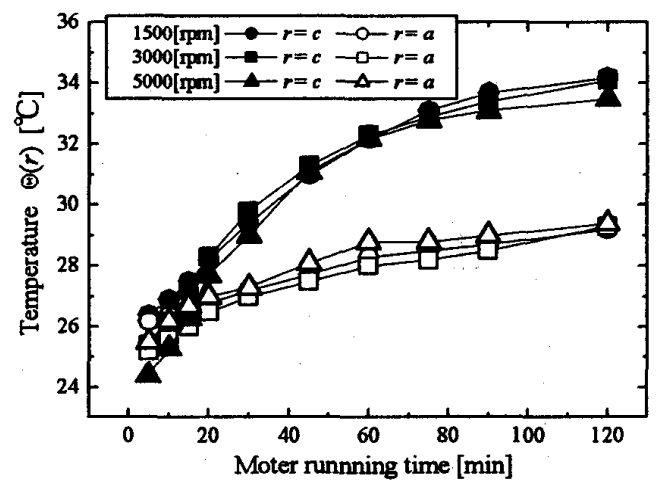

Fig. 7 Transition of the temperature on rotational disk

入れ効果の確認のため，打撃加振試験を行った。打撃 加振では, 加振点から $\theta=180^{\circ}$ 離れた点での変位応答 を渦電流式変位センサ (新川電機(株) VS-15040 L) で 計測した. FFT アナライザ(ヒューレットパッカー ド, HP-35670 A)によって変位応答スペクトルを求 め, 各振動モードの固有振動数を求めた.

$3 \cdot 2$ 回転円板上の温度分布 モータの回転時間 に対する円板の温度分布の推移を図 7 に示す。図 7 か ら，本実験の方法により，内周(フランジ端部)が高温, 外周が低温という温度分布を再現できることを確認し た。また，モータの回転数の違いによって，温度変化 の様子に大きな差が生じないことを, 併せて確認し た.

以上の結果に基づき, 四 7 のうち $1500 \mathrm{rpm}$ のデー 夕を代表として取り上げ，円板の内外周温差に換算し た。結果を図 8 に示す。本実験の範囲では，モータの 運転時間が 90 分以上経過すると, 内外周温度差が一 定值(約 $5^{\circ} \mathrm{C}$ ) に収束した。この結果から，本実験にお いては，回転時間 90 分を経過した時点で, 内外周温度 差は定常に達すると判断した。

$3 \cdot 3$ 固有振動数の変化 円板の温度分布が定常 状態に達した後にモータを停止し，打撃試験を行っ た，得られた変位応答スペクトルを図 9 に示す。前章 


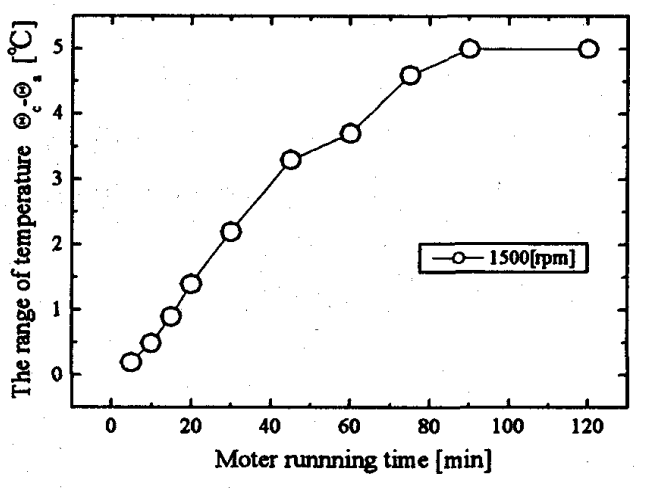

Fig. 8 Transition of the range of temperature between inner and outer of disk

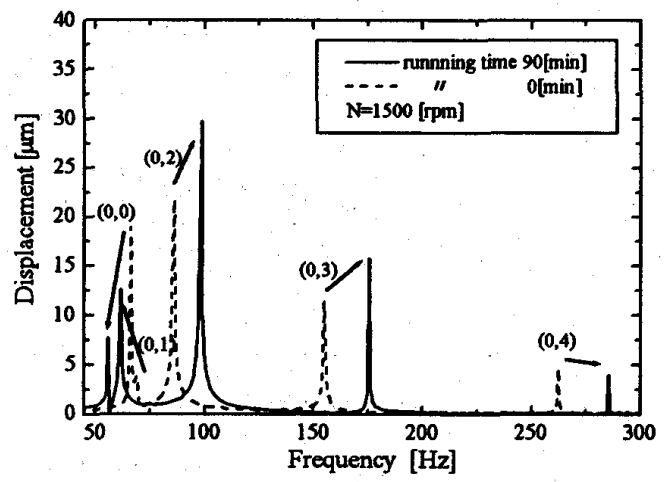

Fig. 9 Natural frequency of the disk

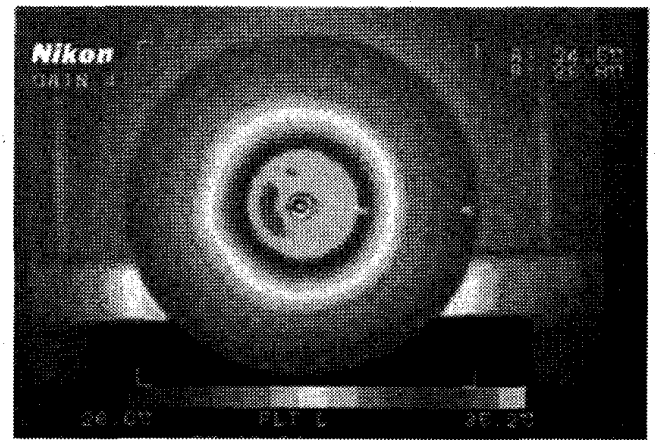

Fig. 10 Temperature distribution of rotating disk

までの解析から推定したとおり，(0,0)，(0,1) 次モー ドの固有振動数が低下し, $(0,2)$ 次以上の固有振動数 が增大する結果が得られた。このことから， $\Theta_{c}$ $-\Theta_{a}>0$ の条件を満たす温度分布により，ローラ腰入 れと同等の効果が得られることを実験的にも確認でき た.

$\mathbf{3 \cdot 4}$ 解析式の妥当性検証 実験において, 温度 分布が定常状態に達したとき $(1500 \mathrm{rpm}, 90 \mathrm{~min})$ の 熱画像計測画面を図 10 に，また，このときの半径方向 温度分布を図 11 にそれぞれ示す，図 11 では，温度分 布の計測結果に対する近似曲線も併せて示した。
Table 2 Comparing natural frequency of disk (compare experiment with calculation)

\begin{tabular}{c|l|c|c}
\hline \multicolumn{2}{c|}{ Mode } & \multicolumn{2}{c}{ Natural frequency [Hz] } \\
\cline { 3 - 4 } \multicolumn{2}{c|}{} & Normal disk & Tensioned disk \\
\hline \multirow{2}{*}{$(0,0)$} & Experiment & 71.18 & 67.78 \\
\cline { 2 - 4 } & Calculation & 70.20 & 61.90 \\
\hline \multirow{2}{*}{$(0,1)$} & Experiment & 65.78 & 64.76 \\
\cline { 2 - 4 } & Calculation & 66.30 & 55.90 \\
\hline \multirow{2}{*}{$(0,2)$} & Experiment & 81.97 & 87.28 \\
\cline { 2 - 4 } & Calculation & 87.50 & 95.25 \\
\hline \multirow{2}{*}{$(0,3)$} & Experiment & 148.72 & 157.76 \\
\cline { 2 - 4 } & Calculation & 158.00 & 170.75 \\
\hline \multirow{2}{*}{$(0,4)$} & Experiment & 256.30 & 267.12 \\
\cline { 2 - 4 } & Calculation & 265.50 & 279.75 \\
\hline
\end{tabular}

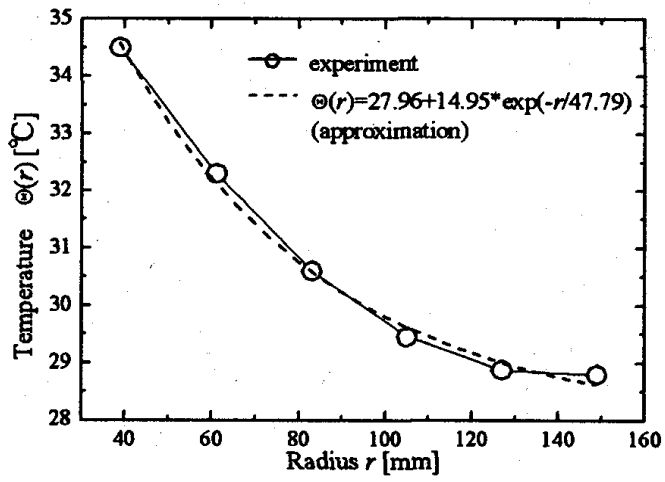

Fig. 11 Temperature distribution of the disk

実験による温度分布は，解析で仮定した定常熱伝導 の曲線では近似できず，指数関数を仮定した場合に良 い一致を示した，具体的には，式(12)で表されるよう な温度分布であった。この違いは，解析では考慮しな かった円板表面から外部空気への熱伝達が，実験にお いて生じていることに起因するものと考えられる.

$$
\Theta(r)=27.96+14.95 \exp \left(-\frac{r}{47.79}\right)
$$

図 7 において, $1500 \mathrm{rpm} て ゙$ 回転させた円板の初期

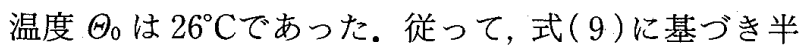
径方向の温度変化量分布 $\Delta \Theta(r)$ は, 次式のように求 まる。

$$
\begin{aligned}
& \Delta \Theta(r)=\Theta(r)-\Theta_{0} \\
& \quad=1.96+14.95 \exp \left(-\frac{r}{47.79}\right)
\end{aligned}
$$

式(13)を式(10)，(11)に代入し，解析方法の妥当性を 検証した。得られた固有振動数の変化を, 実験結果と 併せて表 2 亿示す。

固有振動数の変化量は, 実験結果に比べて, 解析結 果の方が大きくなる傾向が見られた. 熱応力は, 半径 方向の温度勾配にも依存する. 表 2 に打ける実験と解 析の値の差は, 式(13)による近似曲線と実験から得ら 
れる曲線との傾きの誤差に起因するものと考えられ る.ただし, 固有振動数の増減の傾向は, よく一致し た。このことから, 解析に用いた基礎式は, 固有振動 数の増減の傾向を, 解析的に求めるのに妥当な式であ ることが確認できた。

\section{4. 結}

近年, 薄型化が進む丸鋸に扔いて，ロ亡ラ腰入れに 代わる腰入れ方法として, 台金の温度分布を利用する 方法について，円板モデルを用いて解析及び実験によ り検討した。得られた知見を以下に示す。

（1）円板の温度分布を, 定常熱伝導状態と仮定し た解析の結果, 内周側：高温, 外周側：低温とした場 合, 温度差 $\Theta_{c}-\Theta_{a}(>0)$ が大きくなるのに従い, $(0,0),(0,1)$ 次モードの固有振動数が低下し, $(0,2)$ 次 以上の高次モードの固有振動数が増大する傾向が得ら れた.この結果は, ローラ腰入れによる付加応力の大 きさと固有振動数変化の関係と同じ特徵であった。

(2) 内径側：高温, 外形側：低温となる温度分布 を与えた場合, 円板の面内熱応力分布は, 外周近傍に おいて接線方向に引張応力を生じることがわかった. このこともローラ腰入れと同じ特徴であり, 切断抵抗 による座屈を防ぐ効果を有するものと考えられる。
（3）丸鋸の内径側を加熱する方法のひとつとし て, モー夕主軸の発熱を利用する方法を示し, 実験に よって解析の妥当性を確認した。

\section{文献}

(1) Sakai, H., Tipped Saw, (1974), p. 28, Makishoten, (in Japanese).

(2) Iwata, H. and Yoshida, Y., A Basic Study of Tensioning Effect on Rotating Disk Vibration, Transactions of the Japan Society of Mechanical Engineers, Series C, Vol. 58, No. 547 (1992), pp. 684-689.

(3) Munz, U. V. and Thiessen, B., STRAIGHTENING AND TENSIONING OF HIGH HAEDNESS CIRCULAR SAW BLADES BY LASER BEAM, Proceedings of the 16th International Wood Machining Seminar, Part 1 (2003), pp. 234-247.

(4) Noguchi, M. and Umetsu, J., The New Tensioning for Tipped Saw, Journal of the Society of Materials Science, Vol. 37, No. 413 (1988), pp. 240-241.

(5) Bowman, F. (Translated by Hirano, T.), Introduction to Bessel Functions, (1963), Nisshinsyuppan, (in Japanese).

(6) The Japan Society of Mechanical Engineers ed., JSME Mechanical Engineer's Handbook Fundamentals $\alpha 3$ : Materials and Mechanics, (2005), p. 62.

( 7 ) Iwata, H. and Yoshida, Y., Basic Study of Tensioning Effect on Thermally Stressed Disk Vibration, Transactions of the Japan Society of Mechanical Engineers, Series C, Vol. 59, No. 563 (1993), pp. 2015-2019. 